ORIGINAL ARTICLE

\title{
Soy formula complicates management of congenital hypothyroidism
}

\author{
S C Conrad, H Chiv, B L Silverman
}

Arch Dis Child 2004;89:37-40. doi: 10.1136/adc.2002.009365

See end of article for authors' affiliations ....................

Correspondence to: Dr S C Conrad, Children's Hospital Oakland, Division of Pediatric Endocrinology, 747 Fifty Second Street, Oakland, CA 94609 USA;

sconrad@mail.cho.org

Accepted 19 March 2003

\begin{abstract}
Aims: To test the hypothesis that feeding soy formula to infants with congenital hypothyroidism (CH) leads to prolonged increase of thyroid stimulating hormone (TSH).

Methods: The study was a review of 78 patients seen during their first year of life between 1990 and 1998. Data regarding clinical diagnosis, date of treatment initiation, TSH, levothyroxine dose, weight, length, and diet information from each visit were collected from the charts.

Results: There were eight patients in the soy diet group and 70 in the non-soy diet group. There was no significant difference between the two groups in the starting dose of levothyroxine or the change in this dose over one year. There was a significant difference between the two groups in the following areas: time to TSH normalisation, first TSH on treatment, percentage with increased TSH at 4 months of age, percentage with increased TSH throughout the first year of life, and in the overall trend of TSH at each visit. Conclusions: Infants fed soy formula had prolonged increase of TSH when compared to infants fed nonsoy formula. These infants need close monitoring of free thyroxine and TSH measurements, and they may need increased levothyroxine doses to achieve normal thyroid function tests.
\end{abstract}

$\mathrm{T}$ he importance of early and rapid correction of thyroid function tests in infants with congenital hypothyroidism has been shown in a number of recent studies. These show that early diagnosis of congenital hypothyroidism $(\mathrm{CH})$ with neonatal screening programmes and subsequent prompt treatment results in improved developmental outcome ${ }^{12}$ and normal linear growth. ${ }^{3}{ }^{4}$ Widespread implementation of neonatal screening programmes that detect $\mathrm{CH}$ have made early diagnosis an achievable goal.

Other factors, however, may influence outcome in these patients. Soy formula diets are a widely used alternative to milk protein formula diets, and many formulas containing soy are marketed and promoted. Infants are often fed soy formulas because of perceived health benefits of soy or intolerance of other formulas. Prior to the supplementation of soy formula with iodine, and the use of isolated soy protein instead of high fibre soy flour, soy had been reported to cause goitre and hypothyroidism in both humans and animals. ${ }^{5-7}$ However, in recent years, there have been two case reports describing patients with $\mathrm{CH}$ and prolonged abnormal thyroid function tests while on soy formula. ${ }^{8}{ }^{9}$ The reports describe two patients with increased thyroid stimulating hormone (TSH) while on a soy diet and two patients with increased thyroxine (T4) after the soy diet was discontinued. These reports raise questions about dietary influences on $\mathrm{CH}$ treatment.

Our study evaluates the hypothesis that feeding soy formula to infants with congenital hypothyroidism leads to prolonged TSH increase when compared to infants fed nonsoy formula.

\section{METHODS}

The study was a retrospective analysis of patient records. Subjects included patients seen at Children's Memorial Hospital in Chicago throughout their first year of life between 1990 and 1998. Since the routine practice at this hospital is to obtain thyroid scans in all infants with suspected congenital hypothyroidism, patients were identified by thyroid scan records. Ascertainment was verified and supplemented by computerised diagnostic codes used in medical records.
Patients were excluded from the study if they had incomplete records from the first year of life or if they left the clinic before the age of 1 year.

Subjects were categorised in either the soy or non-soy diet group. They were included in the soy diet group if the formula they were on was consistently recorded in the chart as a soy formula throughout the first year of life. As they started taking solid foods these were not exclusively soy containing foods.

The following data were collected from the charts: weight, length, total T4, TSH, levothyroxine dose, thyroid scan result, and diet information from each visit during the first year of life. Since the patients were not necessarily seen at exactly 1 year of age, the last available height and weight in the chart at the time the child was 1 year was used. Using standards from the National Center for Health Statistics, ${ }^{10}{ }^{11}$ a percentile, $\mathrm{z}$ score, and percent median was assigned to each patient for each of the following: height, weight, and weight for height. Aetiology of hypothyroidism was determined by thyroid scan and was considered to be dyshormonogenesis if the thyroid was visible in normal location and hypothyroidism was not transient. Statistical analysis with the Wilcoxon rank sum test, Fisher's exact test, test of fixed effects, and Wilcoxon test for two groups of survival data was performed using SAS software (SAS Institute Inc., Cary, NC).

\section{RESULTS}

\section{Patient characteristics}

There were 99 patients with congenital hypothyroidism identified between 1990 and 1998. Twenty one of these patients were excluded due to incomplete records or discontinuation of clinic visits before the age of 1 year. Thus, there were 78 patients eligible for analysis. Table 1 presents characteristics of these patients. Eight of the patients were included in the soy diet group and 70 of the

Abbreviations: $\mathrm{CH}$, congenital hypothyroidism; $\mathrm{T} 4$, thyroxine; $\mathrm{TSH}$, thyroid stimulating hormone 


\begin{tabular}{|lll|}
\hline \multicolumn{2}{l}{ Table 1 Patient characteristics } \\
\hline & Soy diet group & Non-soy diet group \\
\hline Number of subjects & 8 & 70 \\
Male/female & $4 / 4$ & $29 / 41$ \\
Diagnosis & & 49 \\
Dysgenesis & 6 & 15 \\
$\quad$ Athyreotic & 3 & 34 \\
$\quad$ Ectopic & 3 & 12 \\
Dyshormonogenesis & 1 & 5 \\
Transient & 1 & 2 \\
Down's syndrome & 0 & 2 \\
No scan done & 0 & \\
Reason for referral & & 65 \\
State screen & 8 & 2 \\
Neck mass & 0 & 3 \\
Clinical suspicion & 0 & \\
\hline & & \\
\hline
\end{tabular}

patients were included in the non-soy diet group. There were 33 males and 45 females. Seventy one per cent of the patients had thyroid dysgenesis and $17 \%$ had dyshormonogenesis; the breakdown of diagnoses was similar between the soy and the non-soy diet groups. The vast majority of patients were referred for an abnormal state screen.

\section{Levothyroxine dose}

Table 2 details the initial levothyroxine dose and the change over the first year of life for the soy diet and the non-soy diet groups. The soy diet group was started on treatment at a median age (interquartile range) of 15 days (11.5-22) while the non-soy diet group was started at 17 days (12-23) $(p=0.05)$. There was little difference between the two groups in the starting dose of levothyroxine and the change in that dose over the first year of life. The soy diet group was started on a median dose of $7.4 \mu \mathrm{g} / \mathrm{kg} /$ day $(4.8-10.4)$ compared to $9.3 \mu \mathrm{g} / \mathrm{kg} /$ day $(5.4-11.6)$ in the non-soy diet group $(\mathrm{p}=0.4)$. The change in levothyroxine dose over the first year of life was also similar between the two groups. The soy diet group had a median decrease in dose of $3.3 \mu \mathrm{g} / \mathrm{kg} /$ day $(0.3-5.9)$ compared to $3.0 \mu \mathrm{g} / \mathrm{kg} /$ day $(1.2-5.9)$ in the non-soy diet group $(\mathrm{p}=0.6)$.

\section{Thyroid function tests}

Table 3 also shows thyroid function test results before and after the start of treatment. There was no difference in either the TSH or total T4 levels prior to treatment initiation. The first total T4 levels checked after treatment initiation were similar in the two groups (median $153 \mathrm{nmol} / \mathrm{l}$ in the soy diet group $v 188 \mathrm{nmol} / \mathrm{l}$ in the non-soy diet group, $\mathrm{p}=0.2$ ). There was a difference in the first TSH measured after initiation of treatment between the two groups. The soy diet group had a median TSH of $42.6 \mathrm{mU} / \mathrm{l}(30.6-63.1)$ compared to $6.6 \mathrm{mU} / \mathrm{l}$ $(1.8-20.9)$ in the non-soy diet group $(\mathrm{p}<0.01)$. The timing of the first TSH and T4 after initiation of treatment was similar between the two groups (at a median age of 50 days in both groups).
Normalisation of TSH was also evaluated. The time that it took to achieve a TSH of $<10 \mathrm{mU} / \mathrm{l}$ differed between the two groups. The soy diet group had a TSH $<10$ recorded in the chart by a median of 150 days (54-229) compared to 40 days (19-189) in the non-soy diet group $(\mathrm{p}=0.02)$.

Table 3 shows the percentage of patients with TSH increase after two and four months of treatment. After two months of treatment, there was a higher percentage of patients on soy diets with increased TSH, but this was not significant. At four months, however, $62.5 \%$ of patients in the soy diet group continue to have increased TSH levels compared to $17 \%$ of the non-soy diet group $(\mathrm{p}=0.01)$.

The difference in the percentage of patients with increased TSH between the two groups persisted throughout the first year of their life. Figure 1 shows the equivalent of KaplanMeier curves. The TSH used was the last TSH available prior to the monthly interval in question. The soy diet group had an overall higher and slower descent when compared to the non-soy diet group. The difference between the curves is significant $(\mathrm{p}=0.02)$.

\section{Anthropometric data}

The z scores for each height, weight, and weight for height in the two diet groups were calculated. While the soy group had a non-significantly higher median z score for height ( 0.3 in the soy group compared to -0.2 in the non-soy group) and weight $(0.2 \vee 0.05)$, there was little difference between the two groups in any of the parameters ( $p>0.2$ in all groups) Similar results were obtained when using centile and percent median.

\section{DISCUSSION}

In our population, infants with $\mathrm{CH}$ who were fed soy formula had prolonged increase of TSH. Since normal development is critically dependent on rapid normalisation of thyroid function, this finding has important implications for infants with $\mathrm{CH}$ fed soy formula.

There have been reports in the literature of a subset of patients who have prolonged increase of their TSH. ${ }^{12-15}$ Potential reasons include severity of hypothyroidism, an immature feedback loop, or inadequate dosing. In our subjects, there did not appear to be a difference in the severity of the hypothyroidism based on the soy and non-soy diet groups' similar aetiologies of $\mathrm{CH}$ and similar pretreatment thyroid function tests. An immature feedback loop may exist in some patients, but is unlikely to account for the group differences in TSH reported here. Inadequate dosing needs to be considered in this population. Recommendations for levothyroxine dosing now are certainly higher than when the observations were made of increased TSH in a subset of patients. ${ }^{16}$ The patients in this study were on less than optimal doses of levothyroxine; however, both the soy and non-soy diet groups were on similar doses. It is unclear whether higher doses of levothyroxine would have produced the same effect. In addition, no information was available regarding the length or exclusivity of breast feeding, and no information was available regarding the mothers' diets. These

\begin{tabular}{|c|c|c|c|}
\hline & $\begin{array}{l}\text { Soy diet group } \\
(n=8)\end{array}$ & $\begin{array}{l}\text { Non-soy diet group } \\
(n=70)\end{array}$ & $p$ value \\
\hline Age at treatment initiation (days) & $15(11.5-22)$ & $17(12-23)$ & 0.05 \\
\hline Initial levothyroxine dose ( $\mu \mathrm{g} / \mathrm{kg} /$ day) & $7.4(4.8-10.4)$ & $9.3(5.4-11.6)$ & 0.4 \\
\hline One year decrease in dose $(\mu \mathrm{g} / \mathrm{kg} /$ day $)$ & $3.3(0.3-5.9)$ & $3.0(1.2-5.9)$ & 0.6 \\
\hline
\end{tabular}


Table 3 TSH and T4 before and after starting treatment with levothyroxine

\begin{tabular}{|c|c|c|c|}
\hline & $\begin{array}{l}\text { Soy diet group } \\
(n=8)\end{array}$ & $\begin{array}{l}\text { Non-soy diet group } \\
(n=70)\end{array}$ & p value \\
\hline Pretreatment TSH (mU/l) & $428(154-550)$ & 229 (93-524) & 0.7 \\
\hline First TSH on treatment ( $\mathrm{mU} / \mathrm{l})$ & $42.6(30.6-63.1)$ & $6.6(1.8-20.9)$ & $<0.01$ \\
\hline Pretreatment T4 (nmol/l) & $29.6(22.5-57.3)$ & $47.6(25.1-80.4)$ & 0.2 \\
\hline First T4 on treatment $(\mathrm{nmol} / \mathrm{l})$ & $153(140-180)$ & $188(144-218)$ & 0.2 \\
\hline Time to TSH $<10$ (days) & $150(54-229)$ & $40(18.7-189)$ & 0.02 \\
\hline $\mathrm{TSH}>10$ at 2 months (\%) & 62.5 & 35.7 & 0.2 \\
\hline TSH $>10$ at 4 months (\%) & 62.5 & 17 & 0.01 \\
\hline
\end{tabular}

factors may have played a role for which we were unable to account in this study.

The mechanism of the prolonged increase of TSH in our study is likely related to malabsorption and increased faecal loss of levothyroxine. In animal studies, there have been reports of faecal wastage of T4 while on soy based diets. ${ }^{17}$ This has also been reported in an infant who was refractory to thyroid hormone while on soy formula. ${ }^{18}$ With the newer formulations of soy formula using isolated soy protein rather than high fibre soy flour, one would expect few problems. Our results, however, indicate that it remains a significant issue. This is especially important in patients who are placed on soy formula because of a concern about gastrointestinal problems. These patients may be predisposed to having problems with malabsorption, and the soy formula may trigger or further exacerbate the problem.

It is also possible that soy acts directly on the thyroid gland as a goitrogen. A glycopeptide isolated from soy has been described that blocks iodine uptake and decreases its organification. ${ }^{19}$ More recently, the soy containing isoflavones, genistein and daidzein, were found to be potent inhibitors of thyroid peroxidase catalysed tyrosine iodination. $^{20}$ If this effect were clinically significant, one would expect to find many more cases of hypothyroidism among populations who ingest large quantities of soy products. This has not been reported, so it is unlikely that goitrogen exacerbated iodine deficiency is responsible for the TSH abnormalities that we are reporting. Of note, soy formulas were supplemented with iodine in the 1960s, about the same time that soy formulas were prepared from isolated soy protein rather than high fibre soy flour.

There was no difference in the total $\mathrm{T} 4$ between the soy and the non-soy diet group. It is possible that soy may have an effect on thyroid binding globulin leading to falsely reassuring total T4 values. Soy formulas contain the phytoestrogens genistein and daidzein, and it has been postulated that these

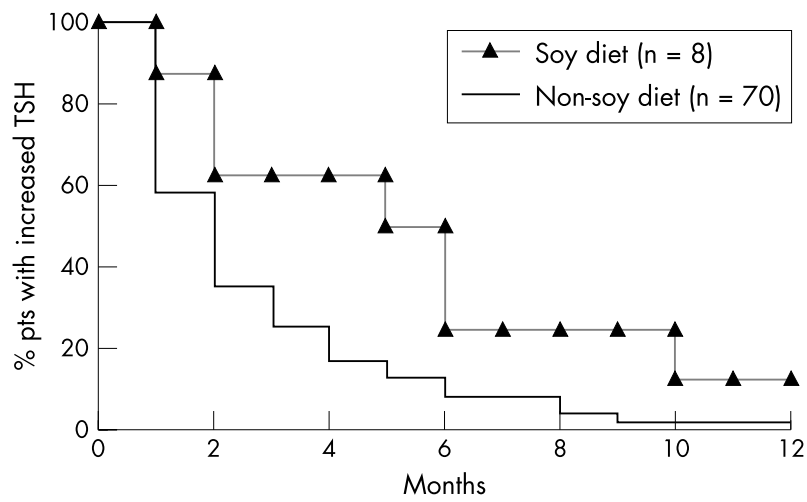

Figure 1 Equivalent of Kaplan-Meier curves for percentage of patients with an increased TSH over time $(p=0.02)$. isoflavones may have biological effects as sex steroids. ${ }^{21}$ Studies in premenopausal and postmenopausal women have shown modest hormonal effects of soy isoflavones. ${ }^{22}{ }^{23}$ It is plausible that the phytoestrogens increase the thyroid binding globulin levels, accounting for a deceivingly normal total T4 in our patients. The free T4, which was not measured, could certainly be low. Unfortunately, this was not measured in our patients. In addition, the sample sizes of the two groups were quite different, and this may have resulted in a lack of power and non-significance of some tests. The results were the same regardless of aetiology of hypothyroidism, but the small size of the soy diet group makes this factor difficult to evaluate.

The ultimate factor in determining the significance of TSH increase in these patients is the outcome data. Our patients did not have any significant differences in their growth parameters at age 1 year. Our results suggest that it would not be prudent to rely solely on growth parameters to determine adequacy of dose. Although measures of neuropsychiatric development are not available, abundant data from the literature suggests that the time to normalisation of thyroid function is critical in the preservation of IQ.

Based on our findings of prolonged TSH increase in patients with $\mathrm{CH}$ on soy formula diets, we recommend that when soy based diets are clearly indicated in patients with $\mathrm{CH}$, the provider must be aware of the possibility of prolonged increase of TSH despite seemingly appropriate doses of levothyroxine. The infant should receive close follow up with free T4 and TSH measurements, and if necessary, increased levothyroxine dose to achieve normal thyroid function tests.

\section{ACKNOWLEDGEMENTS}

The authors would like to thank the Children's Memorial Institute for Education and Research for support of this project.

\section{Authors' affiliations}

S C Conrad, H Chiv, B L Silverman, Department of Pediatrics, Northwestern University Medical School, Chicago, IL, USA

\section{REFERENCES}

1 Bongers-Schokking JJ, Koot HM, Wiersma D, et al. Influence of timing and dose of thyroid hormone replacement on development in infants with congenital hypothyroidism. J Pediatr 2000;136:292-7.

2 Dubuis JM, Glorieux J, Richer F, et al. Outcome of severe congenital hypothyroidism: closing the developmental gap with early high dose levothyroxine treatment. J Clin Endocrinol Metab 1996;81:222-7.

3 Aronson R, Ehrlich RM, Bailey JD, et al. Growth in children with congenital hypothyroidism detected by neonatal screening. J Pediatr 1990;116:33-7.

4 Heyerdahl S, llicki A, Karlberg J, et al. Linear growth in early treated children with congenital hypothyroidism. Acta Paediatr 1997;86:479-83.

5 Beck RN. Soy flour and fecal thyroxine loss in rats. Endocrinology 1958;62:587-92.

6 Van Wyk JJ, Arnold MB, Wynn J, et al. The effects of soybean product on thyroid function in humans. Pediatrics 1959;24:752-60.

7 Hydovitz JD. Occurrence of goiter in an infant on a soy diet. N Engl J Med 1960;262:351-3. 
8 Chorazy PA, Hielhoch S, Hopwood NJ, et al. Persistent hypothyroidism in an infant receiving a soy formula: case report and review of the literature. Pediatrics 1995;96:148-50.

9 Jabbar MA, Larrea J, Shaw RA. Abnormal thyroid function tests in infants with congenital hypothyroidism: the influence of soy-based formula. J Am Coll Nutr 1997; 16:280-2.

10 Waterlow JC, Buzina R, Keller W, et al. The presentation and use of height and weight data for comparing the nutritional status of groups of children under the age of 10 years. Bull World Health Organ 1977;55:489-98.

11 de Onis M, Habicht JP. Anthropometric reference data for international use: recommendations from a World Health Organization expert committee. Am J Clin Nutr 1996:64:650-8.

12 Sato T, Suzuki Y, Taketani T, et al. Age related change in pituitary threshold for TSH release during thyroxine replacement therapy for cretinism. J Clin Endocrinol Metab 1977;44:553-9.

13 Schultz RM, Glassman MS, MacGillivray MH. Elevated threshold for thyrotropin suppression in congenital hypothyroidism. Am J Dis Child 1980;134:19-20.

14 Abusrewil SSA, Tyfield L, Savage DCL. Serum thyroxine and thyroid stimulating hormone concentrations after treatment of congenital hypothyroidism. Arch Dis Child 1988;63:1368-71.

15 Grant DB, Fuggle PW, Smith I. Increased plasma thyroid stimulating hormone in treated congenital hypothyroidism: relation to severity of hypothyroidism, plasma thyroid hormone status, and daily dose of thyroxine. Arch Dis Child 1993;69:555-8.

16 American Academy of Pediatrics. Newborn screening for congenital hypothyroidism: recommended guidelines. Pedatrics 1993;91:1203-9.

17 Van Middlesworth L. Thyroxine excretion, a possible cause for goiter. Endocrinology 1957;61:570-3.

18 Pinchera A, MacGillivray MH, Crawford JD, et al. Thyroid refractoriness in an athyreotic cretin fed soybean formula. N Engl J Med 1965;273:83-7.

19 Koniïin AM, Gershon B, Guggenjein K. Further purification and mode of action of a goitrogenic material from soybean flour. J Nutr 1973;273:83-7.

20 Divi RL, Hebron CC, Doerge DR. Anti-thyroid isoflavones from soybean: isolation, characterization, and mechanisms of action. Biochem Pharmacol 1997:54:1087-96.

21 Irvine CHG, Fitzpatrick MG, Alexander SL. Phytoestrogens in soy-based infant foods: concentrations, daily intake, and possible biological effects. Proc Soc Exp Biol Med 1998;217:247-53.

22 Duncan AM, Merz BE, Xu X, et al. Soy isoflavones exert modest hormonal effects in premenopausal women. J Clin Endocrinol Metab 1999;84: 192-7.

23 Duncan AM, Underhill KE, Xu X, et al. Modest hormonal effects of soy isoflavones in postmenopausal women. $J$ Clin Endocrinol Metab 1999;84:3479-84.

ARCHIVIST

\section{Retropharyngeal abscess}

D escriptions of the clinical features of retropharyngeal abscess (RPA) in textbooks and journals have been varied. Some have described a presentation similar to that of acute epiglottitis, with fever, stridor, and drooling. Others have emphasised neck swelling or non-specific symptoms such as irritability, fever, and refusal to eat. Neck rigidity, neck hyperextension, or meningism have been included and yet others have referred to a paucity of clinical findings. Clinicians in Salt Lake City (Frances W Craig and Jeff E Schunk. Pediatrics 2003;111:1394-8) have reported their experience with 64 children over a 5-year period (1993-98).

During the study period 71 children aged 16 years or under were discharged from the tertiary care children's hospital with a diagnosis of RPA. Six were of traumatic origin and are not discussed any further and one patient was excluded because of lack of imaging confirmation of the diagnosis. Of the 64 study cases 48 (75\%) were under 5 years old and 10 $(16 \%)$ were infants. Four were over 12 years old. Prominent presenting complaints included neck pain (24 patients), fever (11), sore throat (11), neck mass (10), and respiratory distress or stridor (3). In all, 50 had fever, 43 neck pain, 24 sore throat, and 13 cough. Fifty-three patients had limited neck movement and a neck mass was noted in 35 . Only two patients had stridor or wheezing on physical examination and five were described as lethargic or listless. Lateral X-rays of neck were obtained in 44 cases and were described as abnormal in 38, possibly abnormal in three, and normal in three. Computerised tomography was performed on 62 patients and all were abnormal (a condition of entry to the study) but an abscess was reported in only 27 and a possible abscess in 13. For two patients the diagnosis of RPA depended on fluoroscopic findings.

Twenty patients had a blood culture taken but only one produced a growth (Staphylococcus aureus). Swabs taken at operation in 20 cases produced a growth in 17 (group A Streptococcus 13, $S$ aureus 2, Haemophilus influenzae 1, anaerobes 1. Thirty-seven patients recovered on antibiotics alone and 27 had surgical drainage. Surgery was performed on 17 of 27 patients with abscess on CT scan, 8 of 13 with possible abscess, and two of 22 with a CT diagnosis of cellulitis. All 64 patients recovered. Length of hospital stay ranged from one to 13 days and averaged 5 days with surgery and 3 days without.

The clinical features of RPA (or cellulitis) in children are variable but limitation of neck movement, especially of neck extension to look up, is often found. Respiratory distress and stridor are uncommon. Many patients recover with antibiotics alone but surgery may be necessary. CT scanning may demonstrate abscess formation. 